УДК 130.121

DOI: 10.18101/1994-0866-2019-2-65-73

\title{
ПОСТУПОК КАК СПАСИТЕЛЬНОЕ ЧЕЛОВЕЧЕСКОГО ПРОЕКТА
}

\author{
(C) Ильина Ольга Игоревна \\ кандидат философских наук, доцент, \\ Дальневосточный федеральный университет \\ Россия, 690000, г. Владивосток, пос. Аякс, 10 \\ E-mail: olilyina@bk.ru
}

\begin{abstract}
Философская рефлексия темы поступка как события утверждения и осуществления человеческого проекта в области философской антропологии удерживается как минимум двумя сюжетами. Первый - связан с исследованием угроз человеческому проекту в эпоху проникновения проектно-технологического типа организационной культуры во все сферы человеческой жизнедеятельности. Второй - ориентирован на поиск универсального способа, позволяющего занять свое место в бытии и утвердить наличие специфических характеристик человеческого существа: достоинства, воли, мысли, свободы, экзистенции. В статье представлено отношение к угрозам современной социокультурной ситуации как к вызовам, ответом на которые должен стать поступок - утверждение человеческого проекта. Многоуровневость и многоплановость события поступка, многообразие его форм позволяют признать его основным способом утверждения, сохранения и осуществления человеческого проекта. Ключевые слова: бытие; поступок; самоидентификация; ситуация; событие; человеческий проект; проектно-технологический тип организационной культуры; угрозы; экзистенция.
\end{abstract}

Для цитирования:

Ильина О. И. Поступок как спасительное человеческого проекта // Вестник Бурятского государственного университета. Философия. 2019. Вып. 2. С. 65-73.

Проникновение проектно-технологического типа организационной культуры во все сферы жизнедеятельности человека позволило ряду современных философов констатировать закат классического человека и наступления времени постчеловеческого проекта (Г. Тульчинский), времени биотехнической революции и свободы манипулировать человеческой природой (Ф. Фукуяма), не человека в мире, а гуманоидов в техносфере (М. Н. Эпштейн), социальной энтропии и дезорганизации культуры (А. С. Ахиезер) и пр. Сместить фокус внимания с пугающих перспектив на более оптимистичные помогает рефлексивный взгляд на вопросы: Что есть «человеческий проект»? Что в действительности угрожает его осуществлению? Что может явиться в качестве спасительного?

Идея «человеческого проекта» в том или иной артикуляции имеет свою предысторию, которая обнаруживается в попытке схватить цель, способ, суть человеческого существования или взаимопринадлежность человека и бытия, в размышлениях о совершенном или благородном человеке, человеческом достоинстве (Лао Цзы, Конфуций, Платон, Эпикур, Ибн аль-Араби, И. Кант, Г. Гегель, Й. Фихте, Ф. Шиллер, Ф. Ницше, А. Маслоу, Э. Фромм и др.). Однако, чтобы не утонуть в обзоре всех концепций, посвященных наброскам истинной (совершенной) человеческой реальности, сосредоточимся на тех, которые непосредственно указывают на условия возможности человеческого проекта в бытии. 
Данный концепт используется Ж.-П. Сартром для раскрутки идеи о фундаментальной самодостаточности человека в момент осуществления собственного проекта. «Нудительность» осуществления собственного проекта обеспечивается в первую очередь свободой (ничто бытия) и сопутствующими ей экзистенциалами тревогой (за свое бытие), выбором (истины бытия). Ж.-П. Сартр видит источник свободы человека в его недостаточности, неполноте его бытия, в тенденции к уничтожению имеющегося (в настоящем времени) бытия [9]. То есть основание человеческого проекта есть (его) свобода или неполнота человеческого бытия.

Он артикулирует человеческий проект через отношения взаимопринадлежности будущего и настоящего, бытия и небытия. С одной стороны, человек не является тем, чем он будет: между ним и его будущим лежит время; с другой - он является тем, чем он будет в модусе небытия: «...я, каким я являюсь, зависим от себя, каким я еще не являюсь, в такой степени, в которой я, каким я еще не являюсь, не зависим от себя, каким я являюсь» [9, с.101]. Настоящее (бытие) зависит от будущего (бытия) в той же мере, в какой будущее не зависит от настоящего. Будущие или проект уже присутствуют в настоящем как собственная возможность, в той же самой пропорции, будущее или проект не зависят от настоящего. Человеческий проект Ж.-П. Сартра - это событие сбывания человеческого существа. При этом сбывание проекта - зона ответственности человека и его выбора: «Решительный образ действий проистекает из меня, каким я еще не являюсь» $[9$, с.101].

М. Хайдеггер раскрывает идею недостаточности человеческого существа в терминах заброшенности, падения и проекта, которые отражают темпоральную логику озабоченности человеческого существа своим бытием [10].

В качестве прошлого выступает то, что уже есть или случилось, - это заброшенность Dasein. Dasein не само заложило основы своего бытия, а есть и остается заброшенным, детерминированным, захваченным и подчиненным сущим вообще. Dasein не может избавиться от своей заброшенности, но может проектировать те возможности, в которые оно заброшено. То есть Dasein не «совершенно свободен» в своем проекте модификации мира, повседневности, своего будущего. Третий компонент заботы продумывается М. Хайдеггером как падение или забывание истины бытия под напором повседневности. Это мир Man. Оно означает такое отношение человека к бытию, в котором стираются границы между подлинным и неподлинным бытием [10].

Так в чем суть человеческого проекта, если выразить его в терминологии М. Хайдеггера? Человеческий проект - это не самопроизвол человеческого существа: проект - «набросок смысла», «набросок мысли», которые брошены человеку самим Бытием. Но бытие не создается этим проектом, оно «светит человеку в эк-статическом «проекте»»» (здесь бытие еще как бы не есть, но уже есть как своя возможность, которая не отступает, ожидает своей естности). «Событие этого вызывающего посылания - просвет бытия, в качестве которого оно есть» $[10$, c. 205]. Здесь бытие «препоручает» себя человеку.

Несколько иначе проблема человеческого проекта может быть артикулирована с позиции экзистенциальной религиозной философии. Здесь высший замысел человеческого существования угадывается как его энтелехия. Например, у Н. А. Бердяева это рождение Бога в человеке и человека в Боге (Христос-здесь), 
которое есть творческий акт, экстаз, трансцендирование; это рождение нового (абсолютного) человека - андрогина [3].

Для К. Ясперса, балансирующего на границе религиозного и светского философствования, реализация специфического способа существования человека есть уникальность и неповторимость собственной экзистенции, непременное достижение трансценденции (абсолютного бытия). Открытие трансцендентных основ своего бытия приходит к человеку через осознания своей свободы: «Сознавая свою свободу, человек хочет стать тем, чем он может и должен быть» [11, с. 452]. Свобода, данная человеку, позволяет разрывать каузальные связи мира и экзистировать, постигать трансценденцию, обеспечивает действительность самоопределения средствами собственного проекта и выбора способа быть в мире.

В каждую эпоху мыслители стремились артикулировать и концептуализировать угрозы, попирающие человеческое достоинство и условия его возможности. Попробуем сделать набросок в этом направлении, следуя гипотезе, что осуществить, а в современной ситуации человека - защитить и спасти, человеческий проект может только человек, совершающий поступки. Постановка вопроса об угрозе человеческому проекту позволяет: во-первых, сформулировать имена угроз, во-вторых, переформатировать угрозы в ранг вызовов, логика которых ориентирует на ответ, а не на устрашение тенями возможного будущего.

Отношения угроз и человеческого проекта отражает логика отношений ситуации и события. Несмотря на ряд общих характеристик (уникальность, единственность), событие, в отличие от ситуации, характеризуется вневременностью, модификацией всех уровней бытия и сознания, четкими границами своего свершения, внутри которых осуществляется выход за пределы наличного, в то время как ситуация в своем динамическом аспекте ближе к потоку становления (картины мира, бытия, сознания). А. Бадью утверждал, что событие есть производство истины, а ситуация - место, где нечто имеет место [1]. Значит, ситуация может стать местом события, а может и не стать.

Угрозы человеческому проекту в ситуации современного человека обычно возникают, когда тот или иной уровень человеческой организации начинает теснить другие, вызывая опасную деформацию. Если деформация достигает критических размеров, человеческий проект входит в некую точку бифуркации, выходом из которой могут стать либо новые возможности развития человеческого проекта, либо полное прекращение существования человеческого проекта или подмена проекта на до-человеческий / пост-человеческий и пр. Попробуем выделить те угрозы в ситуации современного человека, которые производят впечатление глубоко оппозиционных событию осуществления собственного человеческого проекта.

Первая угроза - это подмена поиска истины веры и разума дискурсивными практиками. Эпоха языковых игр делает веру концептуальной, что сводит ее до уровня теоретических и практических практик, превращает сакральные тексты, удерживающие запредельное, потустороннее к возможностям разума знание (Тертуллиан: «верую, ибо абсурдно»), в поле авантюрных спекуляций для пророков всех мастей и их «комментов». Современный человек находится в ситуации неограниченного выбора того, во что он хочет верить; а он все чаще хочет верить в бессмертие тела как в бессмертие души, во всемогущество генетики, а не духа, в действительность бозона Хиггса, которую Леон Ледерман назвал «частицей 
Бога», а не самого Бога. В это же время научная истина разрывается центробежными силами множества дискурсов, каждый из которых придерживается правил собственной языковой игры. Уже во второй половине прошлого века Ж.-Ф. Лиотар констатировал, что научное знание мутирует в вид дискурса, а наука переходит в сферу производства знания, где критериями истинности признается компетентность, эффективность, результативность, продуктивность и границы дискурса [6].

Другая угроза - отсутствие человека в настоящем времени и пространстве, спровоцированное темпами и масштабами технического и информационного прогресса. Ж. Бодрийяр характеризует современную эпоху как эру гиперреальности, производства и потребления симулякров, где труд не производит, а социализирует, вещи являются мифом, где погруженность в мир тотальных симуляций порождает чувство утраты реальности [4]. Происходит выпадение современного человека из бытия настоящего: он неуместен в «здесь», не удовлетворен «наличным», стремится осуществить выход за пределы - к новому, а область нового это будущее и частично настоящее. Следовательно, современный человек стремится сделать будущее фундаментом наличного существования [8].

Параллельно с отсутствием человека в настоящем времени человек постмодерна выпадает из действительности, а сама действительность теряет свои устойчивые и привычные границы. Внедрение во все сферы жизнедеятельности информационных технологий вынуждает человека воспринимать информационную и цифровую действительность как реальную. Эта тенденция давно вышла за рамки развлечений, когда человек мог оказаться в плену миров из компьютерных игр и интернет-сообществ: на современном этапе информационной фазы целые отрасли перевели свои коммуникации в цифровой режим. Переход в эру цифровой экономики становится реальностью сегодняшнего дня, а с ней внедрение в нашу жизнь электронных паспортов, документооборота, чипизации для якобы обеспечения безопасности и оптимизации администрирования всех сфер жизнедеятельности. Человек просто исчезает из реальности, его представителем в различных электронных сообществах становится его электронный двойник, то есть этакая тень тени человеческого бытия. Здесь отсутствует даже то неподлинное и несобственное бытие из мира Маn (по терминологии М. Хайдеггера), которое хоть как-то гарантировало возможность присутствия. Еще одно замечание: метафора о существовании человека как «тень тени» неслучайна, тень не отбрасывает тень, а значит существование человека в мире цифровой политики, экономики и прочего сводится к ни-что его бытия. И этот «ни-что-житель» человеческого бытия коммуницирует вместо человека с такими же «ни-что-жителями», заменяющими другого человека, организации, государства, приобретает власть над его жизнью, начинает контролировать его свободу, ограничивать его выбор и прочее.

Третий угрожающий момент, спровоцированный темпами смены языковых игр во всех сферах жизнедеятельности, связан с режимом интенсивности перестройки отношений самоидентичности и интегрированности, которые, как показал Э. Гидденс, отражает ряд дилемм самоопределения (унификация - фрагментация; беспомощность - многообразие возможностей; наличие устойчивых авторитетов - самоопределение в условиях их отсутствия; опора на индивидуальный опыт - стандартизированное поведение) [4]. Современные темпы требований к интеграционному ресурсу человека вынуждают его функционировать в 
режиме психических защит, лишая собственных места, времени и сил (воли, ответственности, способностей) для разрешения дилемм самоопределения и самоидентификации.

Еще один угрожающий момент: возможность манипулировать информацией, предлагать и отменять правила игры в науке, политике и экономике и пр. сосредотачивается в руках меньшинства, так называемой мировой элиты, и возможность утраты свободы как гаранта собственного проекта становится уделом всех остальных. Взамен человек приобретает технопространства и цифровые миры, в которых должен ориентироваться и бытийствовать как в естественных для себя, что требует подмены человеческого проекта на какой-либо иной: например, на гуманоидный проект в цифровых техномирах.

Качество угрозы, вытесняющий человека из собственного творчества, приобретает феномен проектно-технологической культуры. Под натиском этого феномена продуцирование знания в науке и культуре превращается из творческого в технологический процесс: поиск истины обеспечивается не вдохновением и интуицией, а следованием алгоритму, отвечающему принятым правилам языковой игры. Эвристический тип мышления как основная способность настоящего ученого замещается проектно-технологическим типом мышления как компетенцией профессионала. А воплощение творческого вдохновения в ряде отраслей искусства превращено в цикл производственной деятельности с соответствующим набором технологий, составляющим основу художественного проекта. Основным результатом проектно-технологической культуры становится отсутствие гениальных открытий в науке и шедевров в искусстве и большое количество ремейков на идеи и образы прошлых лет. И это все на фоне масштабных финансовых вливаний и привлечения больших человеческих ресурсов в эти сферы.

Все рассмотренные выше угрозы (дискурсивность истины, бытийное отсутствие человека в настоящем, ущемление возможностей самоидентификации и проектно-технологическая культура) суть продукты современной социокультурной ситуации, имя которой эпоха проектно-технологической организационной культуры.

В. А. Никитин, исследуя организационный тип современной культуры, пришел к выводу, что со второй половины прошлого столетия происходила смена профессионального типа организационной культуры, в котором знания хранились в форме текста, а формой общественного устройства была профессиональная организация, воспроизводящая себя по принципу онтологических (бытийных) отношений, на проектно-технологический тип, где знания транслируются и созидаются в формах проектов, технологий, программ, а формой общественного устройства становится технологическое общество, структурированное преимущественно по принципу коммуникативности [7].

Итак, современное человеческое существо заброшено в ситуацию, в которой примат проектно-технологической организационной культуры создает прецедент для воспроизводства человека на заказ и отчуждения его от собственного проекта. И эта заброшенность есть исходная точка поиска собственного проекта. Человек как природно-социально-культурно-духовное существо не может быть полностью детерминирован современной социокультурной ситуацией и находиться в полной зависимости от принципов проектно-технологического мира, так как обладает природой и духом. Даже ничтожно малая возможность свободы на од- 
ном из уровней организации бытия может послужить просветом для осуществления события собственного проекта, модифицирующего, как следствие, все планы сознания и уровни бытия. Неконгруэнтность миссий человеческого существа и бытия в осуществлении человеческого проекта: проект воздействует на то, что есть как бытие человека сейчас, но не гарантирует его наличие в конце проекта (и масштабы отсутствия гарантии могут стоить человеку существования), в то время как бытие, которое только «светит в конце проекта» (то есть присутствует как своя возможность), станет наличным без каких-либо гарантий для наличного бытия этого конкретного человека - действительного участника проекта, позволяет утверждать, что по своему исполнению проект - это риск. В тех случаях, когда цена проекта очень высока, а иногда стоит жизни, обычно говорят о подвигах и героях, утвердивших человеческой проект на пределе человеческих возможностей, а их поступки называют геройскими.

История человеческого существа не знает длительных периодов равноденствия всех возможностей его бытия: вся история человека - это история борьбы за право оставаться человеком; это история поступков. Поступок - это не-произвол; это всегда ответ бытию усилиями собственного существа. Поступок обеспечивает двойное усилие: первое - слышать бытие, второе - откликаться. Слышит тот, кто проявляет особою заботу: прислушивается, вопрошает, всматривается в то, что есть, то есть бытие; это может происходить в одно мгновение или как длительная со-настройка. Озабоченность своим бытием стоит понимать как готовность к поступку. Но многие следования призыву бытия, даже если этот призыв очевиден, а человек достаточно восприимчив, в ситуации современного человека отягощены социокультурными обязательствами: правовыми, моральными и прочими ограничениями с их интериоризированными формами.

Человек может разорвать все связи с суррогатами бытия, находясь в аффективном потоке, но такая реакция не обеспечивает действительную свободу. Человек может спрятаться в параллельные миры, идеальные сообщества от своей неполноты, но и это не обеспечит полноты собственного присутствия в бытии. Все формы поведения, исходящие из произволения и избегания подлинного бытия человека, не являются спасительными и, более того, ведут к забвению бытия и блужданию в призрачных мирах.

Принятие поступка в качестве спасительного для человеческого проекта удерживается пониманием феноменальной единственности и целостности многоуровневого и многопланового бытия поступка и его места в бытии человека как события.

Многоуровневость и многоплановость события поступка может быть прояснена через его принадлежность к чувственно воспринимаемому миру и законам свободы (И. Кант); через превращение уровней сознания и бытия: в-себе-бытие (уровень сознания), бытие для-себя (уровень самосознания), бытие для-других (уровень самосознания всеобщей нравственности) (Гегель); через единство сил, порождающих поступок (индивидуального сознания и эмоционально-волевого порыва); единый и единственный контекст значения, правды и смысла поступка; единство форм его выражения (факта, акта, события); многообразие способов проявления (слово, жест, переживание, мысль и пр.); единство модусов: аксиологичность, событийность, единственность, ответственность; архитектонику поступка, удерживающую в едином плане я-для-себя, другой-для-меня и я-для- 
другого (М. М. Бахтин); через фундаментальные условия возможности поступка (экзистенциально-онтологический, культурно-символический, институциональный уровни бытия).

Отношение к поступку как к со-бытию, в котором у человека есть соавтор бытие, артикулируется отечественными мыслителями как «не-алиби в бытие» (М. М. Бахтин), как «не противо-бытие, но со-бытие» (В. Н. Сагатовсий), как «событие с неясным концом» (М. Н. Эпштейн).

Феноменологический профиль предельных условий возможности поступка фиксирует его как событие ответственного утверждения экзистенциальноонтологического переживания через культурную форму выражения; суть которого быть ответом на призыв бытия, в том числе принимающего формы угроз наличной ситуации.

Поступок есть спасительное человеческого проекта, так как он есть событие его осуществления. Универсальность и незаменимость поступка в качестве спасительного удерживается его способностью происходить во всех сферах жизнедеятельности человека. Эта способность связана с многообразием форм поступка (действие, мысль, переживание и пр.), действительность которых обеспечивается выражением многоуровнего и многопланового бытия человека. Мера включенности каждого уровня и плана будет зависеть от того, какие возможности актуализирует конкретный поступок, и отражаться явленностью соответствующей формы поступка.

Поступок один способен преодолеть угрозу превращения истины веры и разума в дискурсивные практики об истине веры, так как сам есть топика присутствия в бытии, в своем свершении удерживает истину бытия, преодолевая все канонические и концептуальные истины всех дискурсивных порядков, и готов утверждать ее заново каждый раз в момент своего свершения (поступок-мысль, поступок-вера).

Поступок - это ответ на угрозу бытийного отсутствия человека в настоящем времени и реальном пространстве: событие поступка возвращает человека в его собственное и подлинное бытие, позволяет редуцировать все разнообразие несобственного и неподлинного, захваченности «миром Мап» (поступок - экзистенция, выход за свои пределы, экстаз к иному).

Поступок выступает гарантом самоидентификации с единицами смысла собственной жизни на основе трансиенденции, а значит, может ответить на угрозы человеческому проекту, связанные с проблемами идентификации.

Поступок может стать спасительным в эпоху проникновения проектнотехнологического культуры во все сферы жизнедеятельности, угрожающей творчеству во многих видах деятельности, так как не ведает проектнотехнологической логики исполнения, и сам в своем осуществлении выходит за пределы всех логик, удерживающих его предписаниями.

Таким образом, рефлексивное отношение к угрозам эпохи проектнотехнологического типа организационной культуры позволяет видеть способы ответа на них: опасность, «давая о себе знать в качестве опасности, есть спасительное» $[10$, с. 255$]$; а значит, ситуацию современного человека можно характеризовать не только как угрозу человеческому проекту или условие становления постчеловеческого проекта, но и как ситуацию, указывающую на условия становления человека-поступка, как место утверждения человеческого проекта. 
Итак, философская аналитика:

- фиксирует человеческий проект как способ изменения грании человеческого бытия, коренящегося в свободе (в ничто человеческого бытия) и в бытии человека. Проект дается человеку как набросок, где бросающее есть само бытие, но осуществляется как со-бытие, где человек есть со-автор проекта бытия как собственного;

- позволяет выделить признаки современной ситуащии, несущие угрозу человеческому проекту: превращение проблемы поиска истины веры и разума и их соотношения в дискурсивные практики об истине веры, науки; бытийное отсутствие человека в настоящем времени и реальном пространстве (уход в интернет и цифровые миры, подчинение техноритмам, сферам потребления); ущемление возможностей самоидентификации; внедрение проектно-технологического типа культуры во все сферы жизнедеятельности человека;

- указывает на поступок как способ осуществления человеческого проекта. Поступок как событие и как топика присутствия в бытии в своем свершении удерживает истину бытия, преодолевая все канонические и концептуальные истины всех дискурсивных порядков; событие поступка возвращает человека в его собственное и подлинное бытие; поступок выступает гарантом самоидентификации с истиной и единицами смысла собственной жизни на основе трансценденции; поступок не ведает проектно-технологической логики исполнения, и сам в своем осуществлении выходит за пределы всех логик, удерживающих его и комментирующих его.

Литература

1. Бадью A. Бытие и событие [Электронный pecypc]. URL: https://fil.wikireading.ru/37869 (дата обращения: 10.10.2018).

2. Бахтин М. М. К философии поступка // Собр. соч. М., 2003. Т. 1. С. 7-68.

3. Бердяев Н. А. Смысл творчества. Опыт оправдания человека. М.: Юрайт, 2017. $256 \mathrm{c}$.

4. Бодрийяр Ж. Симулякры и симуляция / пер. А. Качалова. М.: Постум, 2017. 240 с.

5. Гидденс Э. Устроение общества: очерк теории структурации. М.: Академический проект, 2003. 528 с.

6. Лиотар Ж.-Ф. Состояние постмодерна / пер. с фр. Н. А. Шматко. М.: Ин-т экспериментальной социологии. СПб.: Алетейя, 1998.160 c.

7. Никитин В. А. Организационные типы современной культуры: автореф. дис. ... д-ра культурологии. Тольятти, 1998. 49 с.

8. Павленко А. Н. Возможности техники (Павел Флоренский и Мартин Хайдеггер) // Человек. 2003. № 2. С.71-79.

9. Сартр Ж.-П. Бытие и ничто: опыт феноменологической онтологии. М.: Республика, 2000. $639 \mathrm{c}$.

10. Хайдеггер М. Время и бытие. М.: Республика, 1993. 447 с.

11. Ясперс К. Философская вера // Ясперс К. Смысл и назначение истории. М., 1991. C. 452 . 


\section{DEED AS A SALVATION OF THE HUMAN PROJECT}

Olga I. Ilyina

Cand. Sci. (Philos.), A/Prof.,

Far Eastern Federal University

10 Ayaks, Vladivostok 690000, Russia

E-mail: olilyina@bk.ru

Philosophical reflection of the idea of the deed as an event approving and implementing the human project in philosophical anthropology has by at least two interpretations. The first interpretation is connected with the study of threats to the human project in the era of penetration of project and technology culture into all spheres of human life. The second interpretation is focused on the search for a universal way that will allow one to take his place in being and to confirm the presence of specific characteristics of a human: dignity, will, thought, freedom, and existence. The article presents the attitude to the threats of modern socio-cultural situation as to the challenges, the response to which must be the deed - approval of the human project. The multilevel and multidimensional nature of a deed, a variety of its forms make it possible to recognize it as the main way for approving, maintaining and implementing the human project.

Keywords: being; deed; event; self-identity; situation; human project; project and technology type of organizational culture; threats; existence. 